\title{
Uso que dan a Internet los estudiantes de licenciatura de la Universidad Autónoma de Aguascalientes
}

Lucila Mota Cornejo

T a época actual se caracteriza por la marcada penetración de las tecLnologías de información y comunicación (TIC) en todos los ámbitos de la esfera social. En lo que toca a lo educativo, en el nivel superior, la Declaración Mundial para la Educación Superior en el siglo XXI, ${ }^{1}$ hace un llamado a las instituciones a ser líderes en la adopción y adaptación de las TIC. De este dinámico conjunto de herramientas y procesos centrados en la generación, tratamiento y transmisión de la información, destaca Internet que, como señalan Islas y Gutiérrez, "definitivamente contribuye a reconfigurar todo tipo de instituciones, inclusive las dedicadas a la cultura y a la educación". ${ }^{2}$

Es así que en el marco de la maestría en Investigación Educativa se desarrolló el trabajo de tesis El uso de Internet por los estudiantes en su formación educativa: un estudio en la Universidad Autónoma de Aguascalientes (UAA). ${ }^{3}$ La investigación tuvo como objetivo indagar sobre el uso que dan los estudiantes a Internet para apoyar su formación profesional. Se trata de un estudio con muestra probabilística representativa (nivel de confianza de $95 \%$ y precisión de .05 ) obtenida de la población de estudiantes de licenciatura de la UAA. A continuación, se exponen algunos de los resultados más relevantes que pueden ser de gran utilidad para los docentes de nivel superior, ya que les permite generar reflexiones respecto al uso de Internet dentro de la enseñanza, y el aprendizaje de sus alumnos.

En México, sólo dos de cada diez hogares cuentan con conexión a Internet. ${ }^{4}$ En contraste, Internet es un recurso muy familiar para los jóvenes universitarios: además de que todos lo usan, ocho de cada diez lo tienen en casa y la mayoría son usuarios asiduos, en promedio navegan seis días de la semana con sesiones de hora y media a dos horas. Internet es para los estudiantes de licenciatura de la UAA un recurso eminentemente educativo: nueve de cada diez alumnos lo utilizan en la misma proporción para su aprendizaje académico que para cuestiones distintas y cuatro de cada diez lo usan principalmente para apoyar su formación.

Internet proporciona a los estudiantes de la UAA principalmente la información que necesitan para realizar sus trabajos escolares, es por ello que lo consideran muy valioso para la formación que están recibiendo. Aunque Internet es un medio que se encuentra inserto en la vida cotidiana de los universitarios, se detectó un bajo aprovechamiento de esta potente tecnología. Si bien la finalidad prioritaria es la búsqueda de información para la realización de tareas, ésta se lleva a cabo en páginas poco confiables, con escasa consulta de las bases de datos especializadas que la institución provee. Esto y la poca rigurosidad en el tratamiento de la información develan un problema de alfabetismo

Unesco, Declaración mundial sobre la educación superior en el siglo XXI: visión y acción, 1998. Recuperado el 15 de enero de 2008, en http://www.unesco.org/ education/educprog/wche/ declaration_spa.htm.

O. Islas y F. Gutiérrez, "Teorías e investigación de Internet en México", 2005, en J.C. Lozano Rendón (Ed.), La comunicación en México: Diagnósticos, balances y retos, México, conelcc-Tecnológico de Monterrey, p. 297.

Mota, L., El uso de Internet por los estudiantes en su formación educativa: un estudio en la Universidad Autónoma de Aguascalientes, tesis de maestría, UAA, Aguascalientes, México, 2010.

INEGI, Encuesta Nacional sobre Disponibilidad y Uso de las Tecnologías de la Información en los Hogares, 2009. Recuperado el 07 de mayo de 2010, en http://www. inegi.org.mx. 
informacional. Posiblemente, cumplir con las tareas escolares con apoyo de Internet sea para los estudiantes una actividad más dinámica y flexible, incluso divertida; pero, según las problemáticas reconocidas, no necesariamente más sustancial en términos de aprendizajes significativos y de alfabetización informacional.

Se suma que Internet, aun cuando es un medio que ofrece una amplia gama de recursos de colaboración y producción (foros de discusión, blogs, wikis, etcétera), es muy poco utilizado por los universitarios con fines educativos. Los recursos predilectos, además de las páginas que ofrecen información en texto, son el correo electrónico y mensajero instantáneo, principalmente para comunicarse con compañeros sobre temas relacionados con sus materias. El correo electrónico también es utilizado para intercambiar información con profesores, aunque de manera moderada.

El aprovechamiento de Internet en la educación superior será mayor cuanto más se obtenga ventaja de sus funciones - de información, comunicación e interacción-, a través de la alfabetización e integración. La situación planteada anteriormente, señala un nivel elemental de integración de Internet en los procesos de la enseñanza y el aprendizaje. Debido a que el nivel de integración en la UAA de uso educativo de Internet es básico, es decir de uso auxiliar, ${ }^{5}$ se identifica la necesidad de implementar acciones decididas dentro del contexto institucional para aprovechar el potencial de Internet en la mejora de los procesos de aprendizaje.

Las razones que explican por qué Internet es un recurso generalizado, de acceso casi diario con finalidades eminentemente educativas, no derivan del contexto académico en el que, si bien es cierto se garantiza la disponibilidad, se reconoce muy poca exigencia y asesoramiento en su uso. El uso educativo de Internet no se ve influido significativamente por el papel del profesor en cuanto a exigencia, recomendación o asesoramiento. Esto constituye un llamado a los docentes a tomar una participación más activa en su función como guía y orientador, más aún si se considera que seis de cada diez estudiantes reconocen la necesidad de capacitarse en el manejo de esta tecnología.

La integración de las nuevas tecnologías, como Internet en el modelo presencial, no sólo está en armonía con el paradigma de aprendizaje centrado en el alumno, sino que enfatiza y amplía el rol de los docentes de educación superior. "La nueva tecnología de la información no hace que [los profesores] dejen de ser indispensables, sino que modifica su papel en relación con el proceso de aprendizaje, ya que el diálogo permanente que transforma la información y conocimiento y comprensión, pasa a ser fundamental". ${ }^{6}$

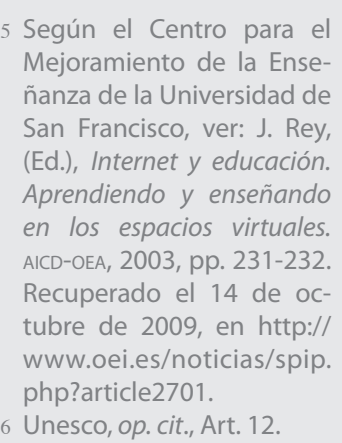




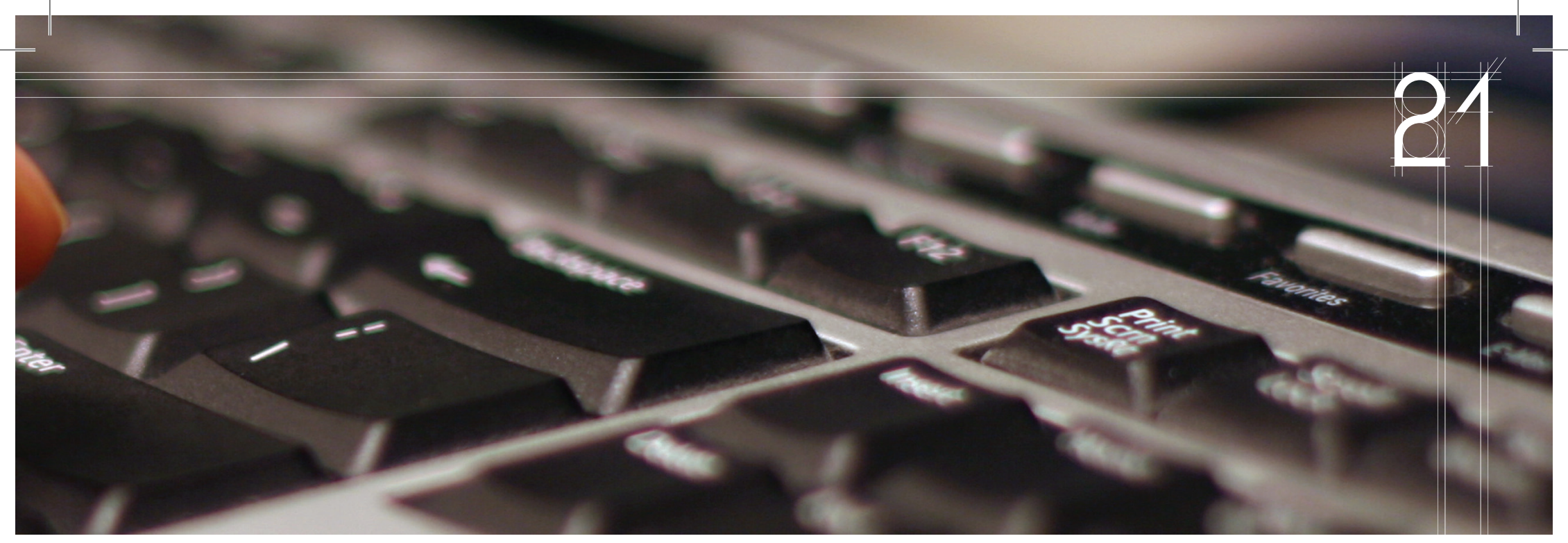

La orientación por parte del profesor en cuanto a las ventajas y desventajas en las prácticas educativas de sus alumnos en relación con el uso que dan a Internet, implica que se involucre en el uso de este medio. Si bien las páginas de información son el recurso privilegiado por los estudiantes, evitar contenidos poco confiables requiere de una evaluación crítica en la búsqueda. Una acción necesaria por parte del profesor para cuidar este aspecto es la supervisión constante de las fuentes de información que los alumnos utilizan. Otra manera sencilla de garantizar el acceso a contenidos de calidad es realizar anticipadamente la revisión de páginas que puedan apoyar los temas que se verán en clase, proporcionar a los alumnos las ligas de las páginas examinadas y pedir la elaboración de trabajos basados en dichos contenidos.

Para un acceso a información de mayor calidad y cientificidad, especialmente cuando se trata de investigar sobre algún tema específico, es necesario que el docente promueva la utilización de las bases de datos especializadas que la institución ofrece, además de apoyar a los estudiantes en el manejo y acceso de estas bases. La orientación adecuada sobre el manejo de fuentes de información basadas en Internet, no sólo resta las posibilidades de que los alumnos "corten y peguen", sino que les permite construir un juicio crítico para la selección de información, desarrollar sus propias ideas y exponerlas de manera sustentada.

En cuanto a los recursos que ofrecen mayor interactividad y productividad, la utilización más habitual de foros o grupos de discusión y del mensajero instantáneo permitirá al docente, además de poder intercambiar materiales de la clases, tareas, trabajos, un mayor acercamiento con sus alumnos; estos recursos también pueden resultar muy útiles para resolver dudas, cohesionar al grupo - e incluso dotarlo de cierta identidad-, promover la libertad de expresión y trabajar en equipo.

En general, el tiempo de clase no es suficiente para exponer y discutir los trabajos de los estudiantes, por lo que la retroalimentación se limita a anotaciones al margen. Una forma de resolver esta dificultad y a la vez de motivar a los estudiantes a la investigación y a la elaboración de trabajos originales, es la utilización de blogs y wikis. Estos recursos, junto con los grupos de discusión, son especialmente adecuados para la participación y productividad de los estudiantes; su utilización, siempre apoyada por el docente, permite la formación de comunidades, que incluso traspasen los límites geográficos locales, sostenidas en el intercambio de conocimientos.

En resumen, desde un simple video, como apoyo a una clase, hasta la utilización de software libre, Internet siempre ofrece múltiples al- 


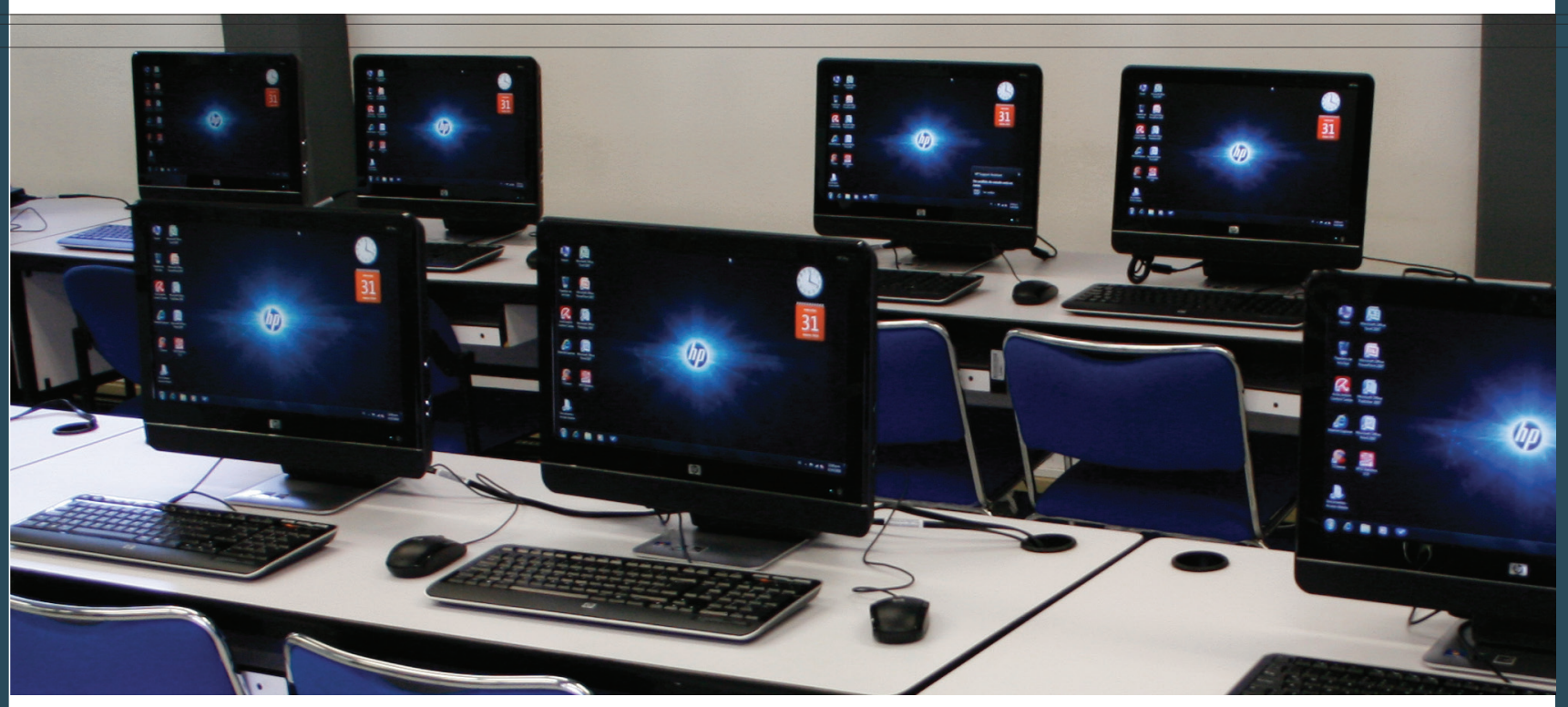

ternativas de apoyo para transformar de manera dinámica la información en conocimiento. La utilización de Internet estará en función de la creatividad del docente y de los alumnos, pero principalmente de los temas y los objetivos de aprendizaje. El aprovechamiento educativo de Internet y de las TIC en general, demanda ante todo una atención y apertura hacia estos medios.

Los retos del nuevo milenio para la mejora de la educación requieren de una renovación. Para ello, resulta ineludible la integración de las TIC en los procesos de la enseñanza y aprendizaje. ${ }^{7}$ La educación en general y las Instituciones de Educación Superior en particular, obligadas a formar personas integrales y competitivas, no podrán estar al margen de tal integración de las TIC ya que, los actuales jóvenes universitarios -y especialmente las nuevas generaciones- conviven de una forma casi "natural" con la tecnología.

\section{Fuentes de consulta}

ANUIES, La educación superior en el Siglo XXI. Líneas estratégicas de desarrollo, México, Autor, 2000.

ANUIES-UPN, Documento estratégico para la innovación en la educación superior, México, Autor, 2004.

INEGI, Encuesta Nacional sobre Disponibilidad y Uso de las Tecnologías de la Información en los Hogares, 2009. Recuperado el 07 de mayo de 2010, en http://www.inegi.org.mx.

Islas, O. y F. Gutiérrez, "Teorías e investigación de Internet en México", 2005, en J.C. Lozano Rendón (Ed.), La comunicación en México: Diagnósticos, balances y retos (pp. 287-301). México, coneicc-Tecnológico de Monterrey.

Mota, L., El uso de Internet por los estudiantes en su formación educativa: un estudio en la Universidad Autónoma de Aguascalientes, tesis de maestría, Aguascalientes, México, UAA, 2010.

Rey, J. (Ed.), Internet y educación. Aprendiendo y enseñando en los espacios virtuales, aicd-oea, 2003. Recuperado el 14 de octubre de 2009, en http://www.oei.es/noticias/spip.php?article2701

UNESCO, Declaración mundial sobre la educación superior en el Siglo XXI: visión y acción, 1998. Recuperado el 15 de enero de 2008, en http:// www.unesco.org/education/educprog/wche/declaration_spa.htm. 